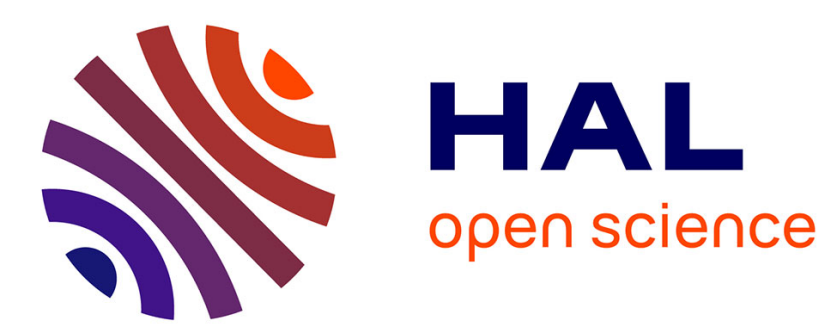

\title{
Ambient vibration recording for single-station, array and building studies made simple: CityShark II
}

Jean-Luc Chatelain, Bertrand Guillier, Philippe Gueguen, J. Frechet, Jacques Sarrault

\section{- To cite this version:}

Jean-Luc Chatelain, Bertrand Guillier, Philippe Gueguen, J. Frechet, Jacques Sarrault. Ambient vibration recording for single-station, array and building studies made simple: CityShark II. International Journal of Geosciences, 2012, 3, pp.1168-1175. 10.4236/ijg.2012.326118 • hal-00790355

\section{HAL Id: hal-00790355 \\ https://hal.science/hal-00790355}

Submitted on 11 Mar 2013

HAL is a multi-disciplinary open access archive for the deposit and dissemination of scientific research documents, whether they are published or not. The documents may come from teaching and research institutions in France or abroad, or from public or private research centers.
L'archive ouverte pluridisciplinaire HAL, est destinée au dépôt et à la diffusion de documents scientifiques de niveau recherche, publiés ou non, émanant des établissements d'enseignement et de recherche français ou étrangers, des laboratoires publics ou privés. 


\title{
Ambient vibration recording for single-station, array and building studies made simple: CityShark II
}

Jean-Luc Chatelain ${ }^{1}$, Bertrand Guillier ${ }^{1}$, Philippe Guéguen ${ }^{2}$, Julien Fréchet ${ }^{3}$, Jacques Sarrault ${ }^{4}$

${ }^{1}$ Institut de Recherche pour le Développement, ISTerre, Grenoble, France

${ }^{2}$ ISTerre - Universté Joseph Fourier, CNRS/IFSTTAR, Grenoble, France

${ }^{3}$ École et Observatoire des Sciences de la Terre, Strasbourg, France

${ }^{4}$ Laboratoire d'Électronique Angelidis Sarrault, Saint Ismier, France

\begin{abstract}
This article describes an improved data acquisition system from a previous system dedicated to one-sensor site studies, aimed at recording ambient vibrations (microtremors). A multi-channel and/or remote triggering system is proposed. The system was conceived by IRD-Leas, France, and used at ISTerre, France, for research activities. The size, weight of this high quality system and its autonomy (no need to be connected to a laptop) make it a real portable device. The system acquires data with 24-bit delta-sigma ADCs in the $10-1000$ sps range at $10-20$ bit resolution on up to 18 channels in the multi-channel version. The input stage dynamics is available at $\pm 2.5 \mathrm{~V}$ or $\pm 5 \mathrm{~V}$. The dynamic range varies, for example, from $108 \mathrm{~dB}$ at 100 sps to $90 \mathrm{~dB}$ at 250 sps. Gain is selectable from $1(0 \mathrm{~dB})$ to $8192(78 \mathrm{~dB})$ by powers of two $(6 \mathrm{~dB})$. Its very low level of internal noise allows recording of very low tension signals without missing code. Continuous recording and GPS may also be implemented in the system, and continuous recording is available. While primarily dedicated to ambient vibration recordings, this system can be connected to any type of instrument delivering an output tension in the $\pm 5 \mathrm{~V}$ range.
\end{abstract}

\section{INTRODUCTION}

CityShark II (Figure 1) is an enhanced version of the CityShark station [1], aimed at single-station, array and building studies using ambient vibration, or any low voltage signal, recordings. It has been developed at ISTerre by IRD, the French Institute for Research for Development, and LEAS, a French company dedicated to geophysical data acquisition.

Although CityShark has been very well rated for use in ambient vibration experiments, and ranked second among 12 tested stations in the SESAME equipment evaluation [2,3,4], the need for such enhancement appeared because CityShark was originally designed to record data from only one sensor, without any time base, aimed at ambient vibration $\mathrm{H} / \mathrm{V}$ and simple building studies. While it rapidly appeared that CityShark proved very adapted and reliable for $\mathrm{H} / \mathrm{V}$ ambient vibration studies [4], the fact that no time reference was used in the data acquisition, as it is not necessary in $\mathrm{H} / \mathrm{V}$ experiments or simple fundamental building frequency determination, turned out to be a burden when considering ambient vibration array experiments and/or determining buildings parameters such as modal deformation, for example. In other words, while possible with a bit of imagination, CityShark was complicated to use in getting synchronous ambient vibration recordings from several places/sites, and a multi-channels option appeared to be essential for array and building applications.

It has therefore been decided to develop an instrument, keeping the simple operating philosophy of CityShark, with new capabilities aimed at getting synchronous recordings.

\section{CITYSHARK II}

CityShark II follows the operating philosophy of CityShark, i.e. (1) all field operations are performed without a computer connected to the station, (2) push-buttons to set up recording parameters, as well as to manage the recording procedure, and (3) the station communicates with the operator through a 20-character 4line LCD built-in screen [1]. As for CityShark, the operating instruction manual simply fits in a single doublesided sheet.

CityShark users will have no surprise: CityShark II is lodged in the same type of case, i.e. it is not more voluminous $(420 \times 335 \times 180 \mathrm{~mm})$, although somewhat heavier $(7 \mathrm{~kg})$ in its 6-sensor configuration mainly because of the use of a more powerful internal battery (12V/7Ah). Also, the same sensor connectors are used (Souriau 851, i.e. Lennartz sensor compatibility). Active sensor(s) is/are powered through the station internal battery, although for longer studies it is possible to connect the station to an external battery or to power it 
with the battery charger. When used with six active sensors the power consumption is $200 \mathrm{~mA}$, with an auto power-off mode in case of low battery voltage.

\subsection{Main new features}

The three main capabilities added to CityShark II are:

(1) CityShark II is available in any configuration to synchronously record one (CityShark II-1) to six (CityShark II-6) 3C sensors, i.e. 3 to 18 channels, by step of 3, a CityShark II-1 being equivalent to the former CityShark;

(2) an option for continuous recording, with data storage into files, which size is chosen by the operator, which allows applications such as short or/and long-term monitoring of structures (Mikael et al., 2012), for example for structural health monitoring. Thanks to the new features (2) and (3), it is now also possible to use CityShark II as an earthquake recording device;

(3) CityShark II may be equipped with an embedded GPS receiver providing the time at start and at end of recording, as well as the site geographical coordinates;

(4) CityShark II may be equipped with a remote triggering device. This option proves very useful to get synchronous records in large array experiment or on large structures such as bridges (over 100-200 m) for which the use of cables might be a constraint. The remote start is triggered using a 0.5 or 5 -watt radio transmitter;

(5) when interrupting a recording before its programmed end, the operator has the choice to either save the recorded data or to delete them, a convenient option to operate CityShark II for short experiments of unknown duration.

\subsection{Other new features}

Several convenient features have been added or changed from the original CityShark configuration: (1) the sample frequency range has been extended to 18 selectable rates in the $10-1000$ sps range, (2) display of actual battery voltage and choice of low-battery voltage cut-off, (3) automatic detection of faulty or unusable flash card, (4) programmable recording start, and (5) programmed repeating recording time in minutes during the first hour. Data download software has been developed for other systems than MS-Windows (see section below).

Future station software updates will be directly available on the LEAS website, and transferred to the station through the station flashcard reader.

\subsection{CityShark II performances}

CityShark II timing is based on a $1.5 \mathrm{ppm}$ TCXO crystal, working in the $-20^{\circ} \mathrm{C}+70^{\circ} \mathrm{C}$ range. The acquisition board comprises up to six modules of three 24-bit delta-sigma ADCs (one module per 3C-sensor), with input stage dynamics available at $\pm 2.5 \mathrm{~V}$ or $\pm 5 \mathrm{~V}$. The dynamic range varies from $108 \mathrm{~dB}$ at 100 sps to 90 $\mathrm{dB}$ at 250 sps. 14 selectable amplifier gains are available, from $1(0 \mathrm{~dB})$ to $8192(78 \mathrm{~dB})$, by powers of two $(6 \mathrm{~dB})$.

\subsubsection{Gain values}

A test performed on gains shows that up to 512 gain values are within $0.001-0.3 \%$ from their nominal values, and from -5 to $-6 \%$ in the $1024-8192$ gain range, while variations throughout the 18 channels are less than $0.3 \%$ in the entire 1 - 8192 gain range. Voltage saturation does not produce any perturbation in the following recorded signal.

\subsubsection{Internal noise, missing code, offsets and anti-aliasing filter}

The first three parameters were evaluated trough statistical tests, performed using histogram techniques (distributions of the number of count values, i.e. the number of times a count value is reached, versus count values). The tests were first performed by recording the signal obtained without any sensor connected to any of the 18 channels, the entries being not short-circuited. In a second series of tests a $1-\mathrm{k} \Omega$ resistor has been connected between the two signal pins (+ and -) of the 18 input channels. Recordings were performed at 100 sps in both cases, on a CityShark II-6 and a CityShark II-1 respectively.

The average internal noise level reaches a value of $\pm 1 / 131072$ counts $( \pm 19 \mu \mathrm{V})$ at gain 1 (Figure 2) and $\pm 15 / 131072$ counts $( \pm 0.035 \mu \mathrm{V})$ at gain 8192 . This high signal-to-noise ratio permits CityShark II to record very low amplitude signals, allowing, for example, to get a $0.4 \mathrm{~Hz} \mathrm{H} / \mathrm{V}$ peak from a $4.5-\mathrm{Hz}$ seismometer (Figure 3).

These results also show that there is no missing code, as there is no "hole" in the number of count values, i.e. count values that are not reached within the distribution range, to the contrary of what is encountered with 
some other types of data acquisition systems [5]. Offsets are within \pm 15 counts $( \pm 275 \mu \mathrm{V})$ at gain 1 and \pm 13600 counts $( \pm 32 \mu \mathrm{V})$ at gain 8192 .

The anti-aliasing filter has been tested by recording, at $125 \mathrm{sps}, 2.5$-Volt sine waveforms with frequencies varying from $12.5 \mathrm{~Hz}$ up to $375 \mathrm{~Hz}$. To the contrary of what is observed for other recording devices, the CityShark II anti-aliasing filter works fine (Figure 4).

\subsubsection{Synchronism in-between channels}

A simultaneous recording of the same $1 \mathrm{~Hz}$ triangle-shape signal by all of the 18 CityShark II channels has been completed at $100 \mathrm{sps}$, using various gains. Then, in order to check their synchronism, the signal differences have been performed, after removing the trace offsets. As in the precedent test, results are shown as the distributions of the number of count values versus count values, which in this case should be Gaussian curves centered on zero, the deviations from zero being due to the combined effect of internal noise and the slight variations in gain value in-between channels. The results show a perfect synchronism between channels, as we indeed do obtain Gaussian curves centered on 0, without missing values (Figure 5). These curves also confirm that the combined effect of internal noise and variations in gain in-between channels is negligible.

\subsubsection{Synchronism in-between stations using remote triggering}

The synchronism of recording start-up in-between several stations when using the remote triggering has been evaluated by recording the logical level of 7 station receivers on an oscilloscope in two series of 4 , with a reference station. The average delay is about $60 \mu \mathrm{s}$, with a maximum of about $125 \mu \mathrm{s}$ (Figure 6).

\section{OPERATING CITYSHARK II}

\subsection{Recording data}

CityShark II works in a similar way to CityShark. Parameters and internal time settings are completed on the station itself, without connecting an external computer, with the help of two press-buttons labeled "gain up" and "gain down", with basically only three recording parameters to set up: gain, sample rate, and recording duration. Optional parameters can be set-up: the maximum percentage of clipped samples allowed during a record, a period of repeated recording, overwriting the default file index used in the data file. The signal level is indicated by a bar-graph on the built-in screen. For a more detailed description of operating CityShark, and on the way it works, see [1].

\subsection{Retrieving data}

CityShark II stores recorded data on a removable flash memory card, with storage capacity ranging from $32 \mathrm{MB}$ to $4 \mathrm{~GB}$. The flash card must be formatted and prepared on an external computer before its first operation. Once the data have been recorded, the flash card is read on a PC using ReadCity, software developed specifically to handle the CityShark data format for MS-Windows (Figure 7), Linux and Mac OSX systems. In the CityShark II station, data records are written on the flash card into a single large binary file, each record including a small header containing all relevant parameters. ReadCity allows to select some of or all these records, and to download them to the PC as ASCII files in a spreadsheet-ready format (Figure 8) or as binary files, at the operator convenience. After downloading in ASCII format it is possible to include any commentaries in the header, as long as they are added in-between the first and last line of the actual header. After saving the data, ReadCity can prepare the flash card for a new recording session by erasing all records and initializing the flash card header. Data are however not physically erased from the card, and a ReadCity option allows to retrieve them in the case of a mistakenly erasure, as long as no new record has been performed. Data analysis can be performed with standard scientific software or ambient vibration processing dedicated software. Alternatively, data files can be directly downloaded into the seismic SAC format, allowing using the large library of seismic software based on this format.

\subsection{Results}

CityShark II has been successfully used in various types of ambient vibration studies: buildings (Figure 9, and [6-11]), ground arrays (Figure 10, and [12-15]), landslides [15] and single-station (H/V) [Figure 3, and $[16-22]$.

\section{CONCLUSION}

CityShark II is a very user-friendly instrument specially designed to meet a wide range of ambient vibration recording applications such as array or building dynamics studies, or any kind of low voltage signal, avoiding all unnecessary recording parameters that are part of operating a station devoted to earthquake recording. Portability of the station is assured through the station lightweight and its independence from external devices, 
i.e. external battery and computer. It is very easy to use by a non-specialist. Synchronous data acquisition for large size array or structure ambient vibration studies is made easy by using remote triggering, or postsynchronization during data processing when using GPS time.

With the continuous recording and GPS options CityShark II can also be used for earthquake recording operations.

Statistical tests, performed using histogram techniques, used to evaluate gain variations, offsets, absence of missing code, internal noise level, remote triggering and in-between channels synchronism proved CityShark II to be a very reliable data acquisition system.

The data software package, provided with the station, allows to format the flash card and retrieve data in ASCII spreadsheet-ready format, in an easy and time-effective way producing very easy to handle data files, or directly in Sac format. The software runs under the most common systems (MS-Windows, Linux, Mac OSX).

Finally, while mostly used in the framework of ambient vibration studies, CityShark II can handle any kind of low voltage signal.

\section{ACKNOWLEDGEMENTS}

We had fruitful discussions with P.-Y. Bard, F. Dunand, and S. Bonnefoy-Claudet, who also helped to test Cityshark II through its validation process. This project has been funded by IRD (Institut de Recherche pour le Développement), a French public research institute, and LEAS company. Save public research.

\section{REFERENCES}

[1] J.-L. Chatelain, P. Guéguen, B. Guillier, J. Fréchet, F. Bondoux, J. Sarrault, P. Sulpice, J.-M. Neuville, "CityShark: A user-friendly instrument dedicated to ambient noise (microtremor) recording for site and building response studies," Seismological Research Letters, Vol. 71, 2000, pp. 698-703.

[2] B. Guillier, K. Atakan, A.-M. Duval, M. Ohrnberger, R. Azzara, F. Cara, J. Havskov, G. Alguacil, P. Teves-Costa, N. Theodulidis, and the SESAME Project WP02-Team, Proceedings of the 27th General Assembly of the European Geophysical Society, Nice, France, 22-26 April 2002.

[3] B. Guillier, K. Atakan, J.-L. Chatelain, J. Havskov, M. Ohrnberger, F. Cara, A.-M. Duval, S. Zacharopoulos, P. Teves-Costa and the SESAME Team, "Influence of instruments on the H/V spectral ratios of ambient vibrations," Bulletin of Earthquake Engineering, Vol. 6, 2008, pp. 3-31. doi:10.1007/s10518-007$\underline{9039-0}$

[4] SESAME, European Commission - Research General Directorate Project No. EVG1-CT-2000-00026 SESAME, report D01.02, 2002, 250 pp.

[5] R. Pillet, "Missing Code et filtre anti-aliasing de deux acquisitions numériques," 2002. http://wwwgeoazur.unice.fr/PERSO/pillet/page-mcfaa2an.html

[6] C. Michel, P. Guéguen, P.-Y. Bard, "Dynamic parameters of structures extracted from ambient vibration measurements: An aid for the seismic vulnerability assessment of existing buildings in moderate seismic hazard régions," Soil Dynamics and Earthquake Engineering, Vol. 28, No. 8, 2008, pp. 593-604. doi:10.1016/j.soildyn.2007.10.002

[7] M.N. Farsi, B. Guillier, J.-L. Chatelain, S. Zermout, "Retrofitting and strengthening evaluation from stiffness variations of a damaged building from ambient vibration recordings," In: Increasing Seismic Safety by Combining Engineering, M. Mucciarelli et al. (eds.), NATO Science for Peace and Security, Series C: Environmental Security, Springer Sciences, 2009, pp. 227-238.

[8] C. Michel, P. Guéguen., S. El Arem, J. Mazars, P. Kotronis, "Full Scale Dynamic response of a RC building under weak seismic motions using earthquake recordings, ambient vibrations and modelling," Earthquake Engineering and Structural Dynamics, Vol. 39, 2010, pp. 419-441. doi:10.1002/eqe.948 
[9] P. Guéguen, "Experimental analysis of the seismic response of an isolating building according to different levels of shaking: example of the Martinique earthquake (2007/11/29) Mw 7.3," Bulletin of Earthquake Engineering, Vol. 10, No. 4, 2012, pp. 1285-1298. doi:10.1007/s10518-012-9355-X

[10] F. Dunand, P. Guéguen, "Comparison between seismic and domestic risk in moderate seismic hazard prone region: the Grenoble City (France) test site," Natural Hazards and Earth System Sciences, Vol. 12, 2012, pp. 511-526. doi:10.5194/nhess-12-511-2012

[11] C. Michel, P. Guéguen, M. Causse, "Seismic vulnerability assessment to slight damage based on experimental modal parameters", Earthquake Engineering and Structural Dynamics, Vol. 41, No. 1, 2012, pp. 81-98. doi:10.1002/eqe.1119

[12] B. Guillier, J.-L. Chatelain, M. Hellel, D. Machane, N. Mezouer, R. Ben Salem, E.-H. Oubaiche, "Smooth bumps in H/V curves over a broad area from single-station ambient noise recordings are meaningful and reveal the importance of Q in array processing: The Boumerdes (Algeria) case," Geophysical Research Letters, Vol. 32, No. 24, 2005, L24306. doi:10.1029/2005GL023726

[13] M. Hellel, J.-L. Chatelain, B. Guillier, D. Machane, R. Ben Salem, E. H. Oubaiche, H. Haddoum, "Heavier damages without site effects and site effects with lighter damages: Boumerdes City (Algeria) after the may 2003 earthquake," Seismological Research Letters, Vol. 81, No. 1, 2010, pp. 37-43. doi:10.1785/gssrl.81.1.37

[14] M. Hellel, E. H. Oubaiche, J.-L. Chatelain, D. Machane, R. Ben Salem, B. Guillier, G. Cheiklounis, "Basement mapping with single-station and array ambient vibration data: Delineating faults under Boumerdes city (Algeria)," Seismological Research Letters, Vol. 83, No. 5, 2012, pp. 798-805. doi: $\underline{10.1785 / 0220110142}$

[15] P. Lacroix, M. Wathelet, L. Tatard, B. Guillier, F. Bondoux, J. Marino, E. Taipe, B. Zavala, P. Valderrama, L. Fidel, J.-C. Gomez, E. Norabuena, "Caracterización de los procesos sismicos y gravitacionales sobre el deslizamiento de Maca (Colca, Peru)," XVI Congreso Peruano de Geologia \& SEG, 2012, Lima, Peru

[16] P. Guéguen, J.-L. Chatelain, B. Guillier, H. Yepes, J. Egred, "Site effect and damage distribution in Pujili (Ecuador) after the 28 March 1996 earthquake," Soil Dynamics and Earthquake Engineering, Vol. 17, 1998, pp. 329-334.

[17] P. Guéguen, J.-L. Chatelain, B. Guillier, H. Yepes, "An indication of the soil topmost layer response in Quito (Ecuador) using H/V spectral ratio," Soil Dynamics and Earthquake Engineering, Vol. 19, 2000, pp. 127-133.

[18] A.A. Panou, N. Theodulidis, P. Hatzidimitriou, K. Stylianidis, C.B. Papazachos, "Ambient noise horizontal-to-vertical spectral ratio in site efsfects estimation and correlation with seismic damage distribution in urban environment: the case of the city of Thessaloniki (Northern Greece)," Soil Dynamics and Earthquake Engineering, Vol. 25, 2005, pp. 261-274. doi:10.1016/j.soildyn.2005.02.004

[19] B. Guillier, J.-L. Chatelain, S. Bonnefoy-Claudet, E. Haghshenas, "Use of ambient noise: from spectral amplitude variability to H/V stability," Journal of Earthquake Engineering, Vol. 11, No. 6, 2007, pp. 925942. doi:10.1080/13632460701457249

[20] J.-L. Chatelain, B. Guillier, I. A. Parvez, "False site effects: the Anjar case, following the 2001 Bhuj (India) earthquake," Seismological Research Letters, Vol. 79, No. 8, 2009, pp. 698-703. doi:10.1785/gssrl.79.6.816 
[21] R. Ben Salem, J.-L. Chatelain, D. Machane, E. H. Oubaiche, M. Hellel, B. Guillier, M. Djeddi, L. Djadia, "Ambient vibration techniques applied to explain heavy damages caused in Corso (Algeria) by the 2003 Boumerdes earthquake: Understanding seismic amplifications due to gentle slopes," Seismological Research Letters, Vol. 81, No. 6, 2010, pp. 928-940. doi:10.1785/gssrl.81.6.928

[22] E. H. Oubaiche, J.-L. Chatelain, A. Bouguern, R. Ben Salem, D. Machane, M. Hellel, F. Khaldaoui, B. Guillier, "Experimental relationship between ambient vibration $\mathrm{h} / \mathrm{v}$ peak amplitude and shear-wave velocity contrast," Seismological Research Letters, 2012, accepted. 


\section{FIGURE CAPTION}

Figure 1. View of a CityShark II-6 station.

Figure 2. Examples of histograms of count values from recordings obtained without any sensor connected to CityShark II for channels 1-3 (top, A) and channels 10-12 (bottom, B). Recordings were made at 100 sps and gain 1 . The internal noise obtained from the half width of the Gaussian curves has a value of 1 . The curves are centered on the channel offset value, which reached a maximum of 15 . No "missing code" is evidenced, as within each curve all count values are reached.

Figure 3. Comparison of $\mathrm{H} / \mathrm{V}$ curves from ambient vibration recordings, with a $0.4 \mathrm{~Hz}$ peak, obtained with a 5-second Lennartz seismometer (left) and a Mark Products $4.5-\mathrm{Hz}$ seismometer (right) on the same ground site. The very low level of internal noise of CityShark II results in a very high signal/noise ratio, which allows obtaining the same peak frequency value $(0.4 \mathrm{~Hz})$ with both the $4.5-\mathrm{Hz}$ and the 5 -second seismometer, even though it is way below the $4.5-\mathrm{Hz}$ seismometer frequency cut-off. Understandably, though, the $\mathrm{H} / \mathrm{V}$ amplitude of the peak is lower when using the $4.5-\mathrm{Hz}$ seismometer.

Figure 4. Maximal count values from 2.5 Volts sine waveforms with frequencies in the $12.5-375 \mathrm{~Hz}$ range recorded at $125 \mathrm{sps}$ at gain $1 \mathrm{using}$ a $10 \mathrm{~V}$ dynamic range CityShark II, showing the behavior of the antialiasing filter.

Figure 5. Examples of test of the synchronism in-between the 18 CityShark II channels. The same $1 \mathrm{~Hz}$ triangle is sent simultaneously on the 18 channels at 100 sps. The top of the figure (A and B) show002 s the differences in-between channels of the same acquisition board (channels 2 to 3), at gain 1 (A) and 8192 (B). The bottom of the figure (C and $\mathrm{D})$ shows the differences in-between channels of different acquisition boards (channels 1, 7 and 18), at gain 1 (C) and 8192 (D). The only differences come from the slight gain variations from one channel to another, evidenced by the differences of the top values of the Gaussian curves.

Figure 6. Example of starting time delays from 7 CityShark II-1 when using the remote triggering. Starting time is indicated by a downward step.

Figure 7. ReadCity screen under MS-Windows system. ReadCity shall be used to download CityShark data from a flash card, and to erase data.

Figure 8. Example of a CityShark II 3-channels data file retrieved using ReadCity. The original file name is transformed by adding the year, obtained from the internal date of the computer with which the data is retrieved, and hour minute are separated from the rest of the name by an underscore. File name may also include sensor number (1 to 6) when recording several sensors (e.g. Capt_1_050430_1612.001, and/or the station serial number (e.g. 050430_1612.001_001.001, Capt_1_050430_1612.001_001.001); the latter should be used when recording from several stations with the same time set. The conversion factor is the value by which following data, in counts, should be divided to get data in Volts at gain 1. This value should be divided by the gain for gain values over 1 . Dynamic range is the full dynamic range (e.g. 5 Volts for \pm 2.5 Volts). Maximum amplitude is the maximum absolute count value reached by the data. Other header parameters are self-explanatory. Commentaries may be included in the header in-between the first and last line, which must not be changed. Data are listed as a sample per line, in counts, in the Z, N-E, E-W order, i.e. signal from the A-B, C-D, and E-F input connector pins respectively.

Figure 9. Example of determination of the transversal and longitudinal vibration modes of a 28-storey building from ambient vibrations simultaneously recorded with a CityShark II-6 station using five 4.5-Hz sensors (left). The fundamental frequency and the $1^{\text {st }}$ harmonic are clearly showing up. Higher modes need a zoom of the figure to show up. The first three modes of longitudinal deformations (right) are obtained from the amplitudes of the figure on the left. 
Figure 10. Example of result from a 8-sensor array ambient vibration recordings. Two 1-channel and one 6channel CityShark II were used, with remote triggering. The seismic shear-wave velocity model (right) is obtained from the Rayleigh wave dispersion curve (left). 


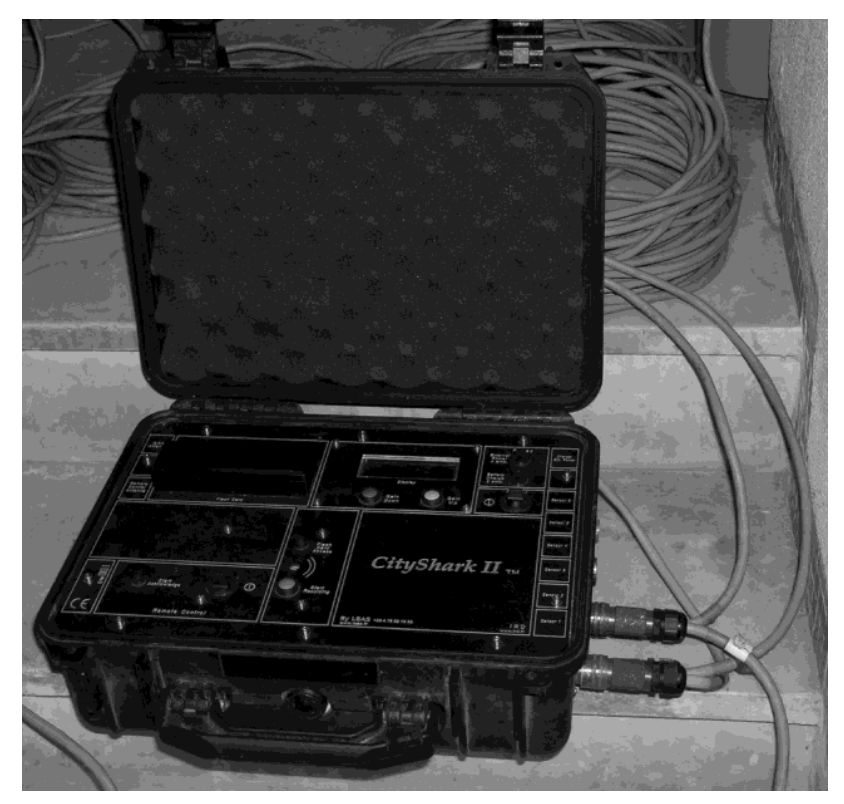

Figure 1
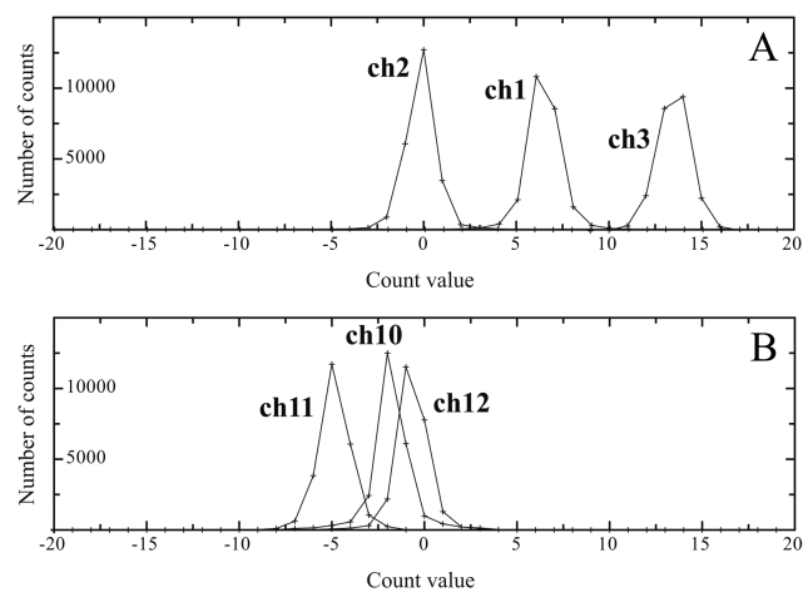

Figure 2 

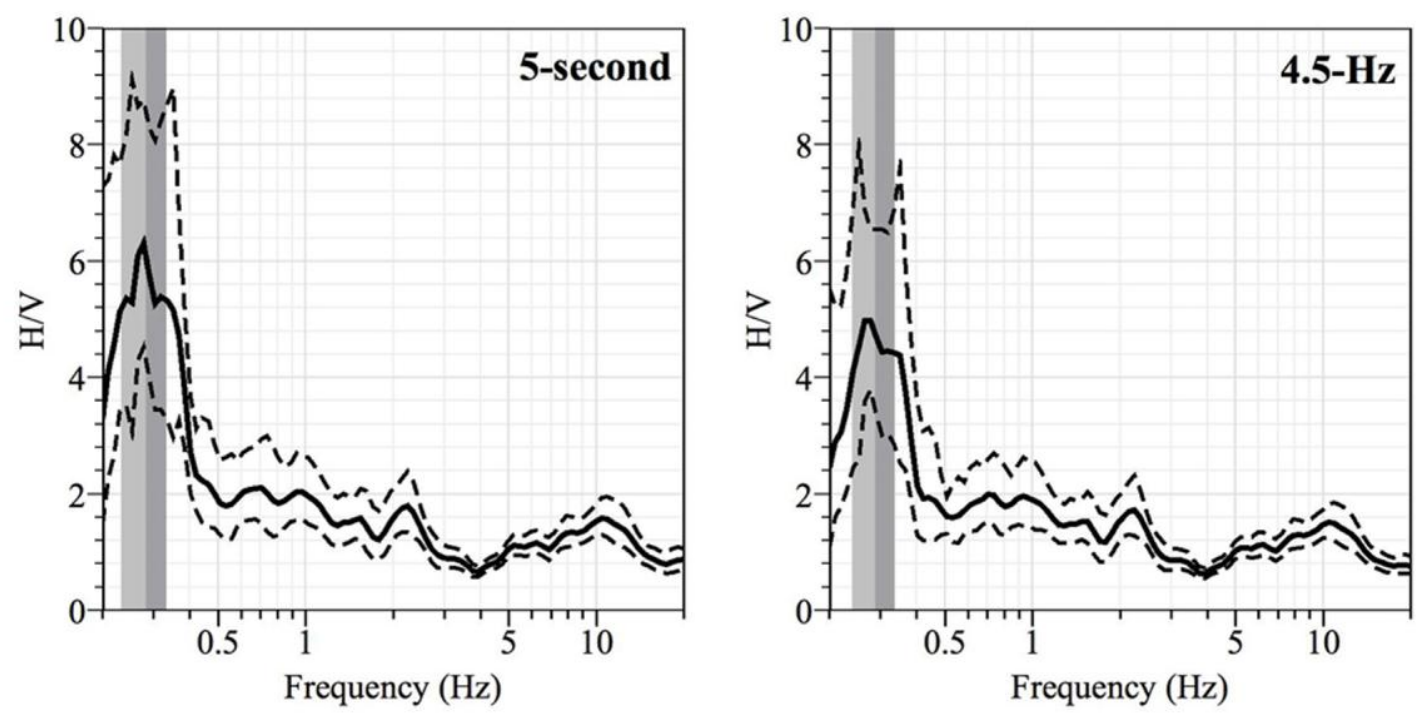

Figure 3

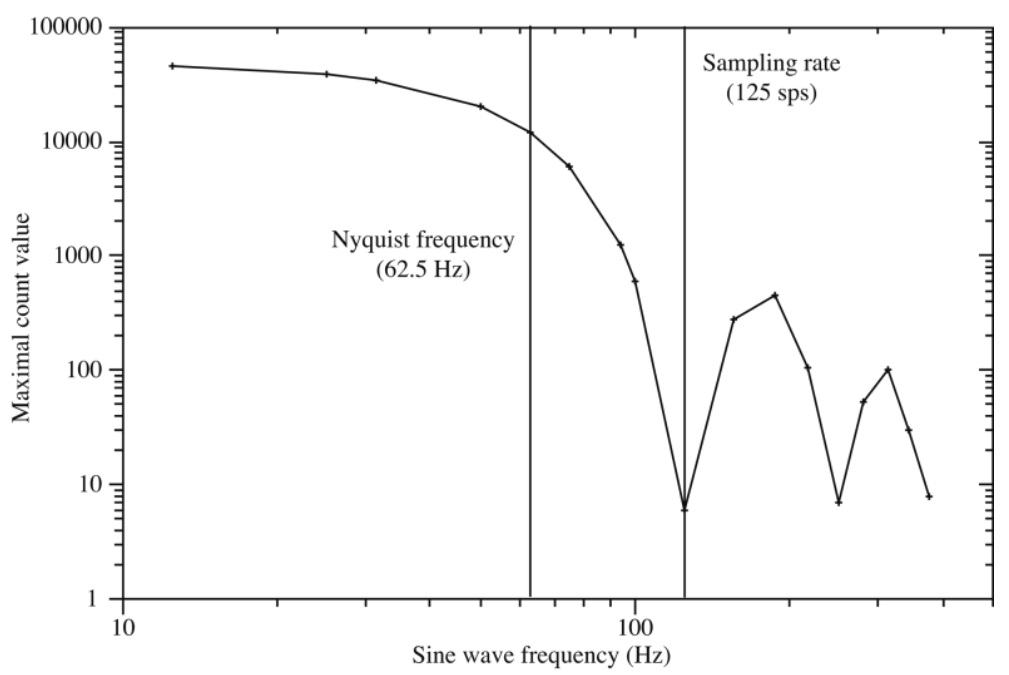

Figure 4 

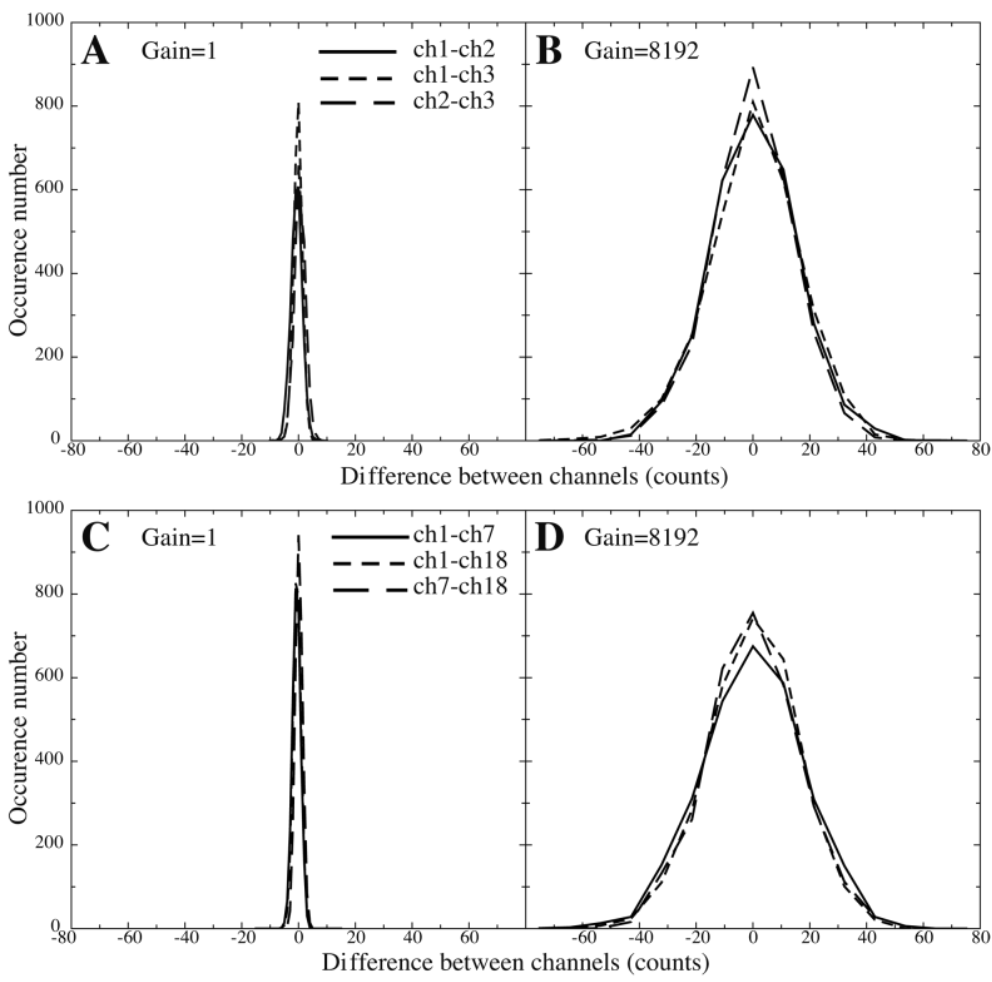

Figure 5

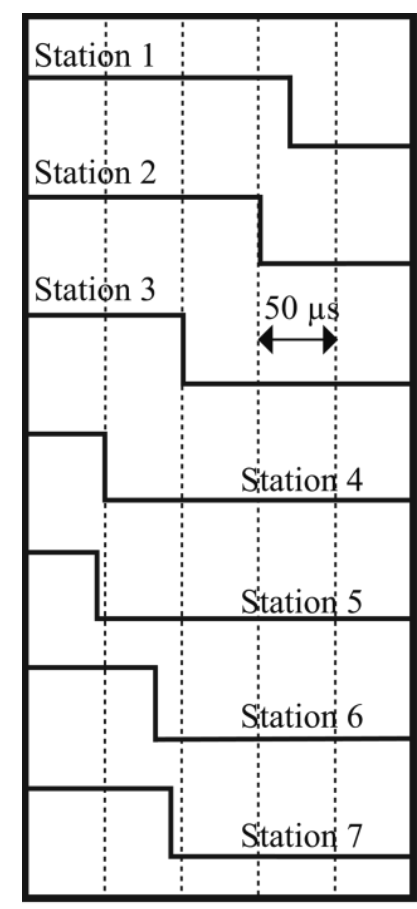

Figure 6 


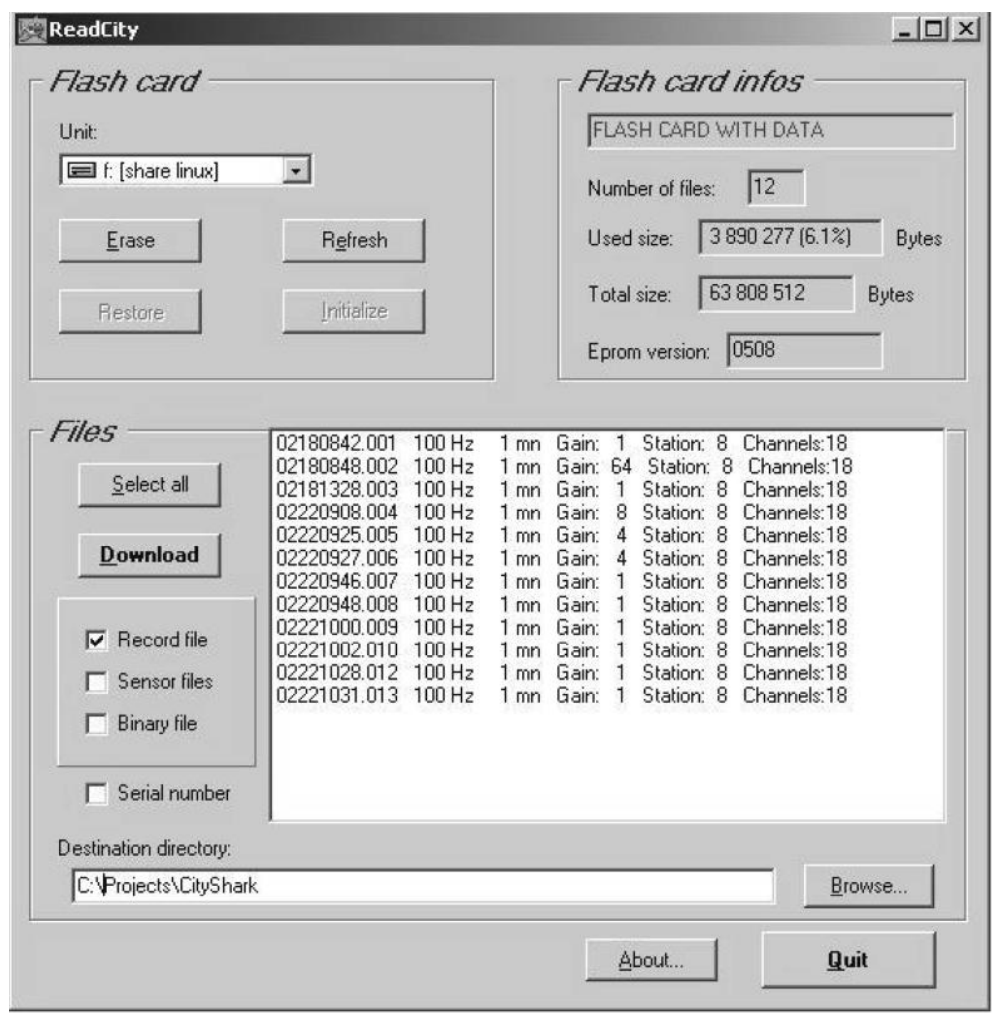

Figure 7

Original file name: 04301612.001

Transformed into: 050430_1612.001

ReadCity version: 3.0

Station serial number: 001

Station software version: 0436

Channel number: 3

Starting date: 30.04 .2005

Starting time: $16: 12: 42.768$

Ending date: 30.04 .2005

Ending time: 16:27:42.763

Sample rate: $100 \mathrm{~Hz}$

Sample number: 90000

Recording duration: $15 \mathrm{mn}$

Conversion factor: 52428.8

Gain: 16

Dynamic range: $5 \mathrm{~V}$

Clipped samples: $0.77 \%$

Latitude : 451.575

Longitude: 26.849

Altitude : $243 \mathrm{~m}$

No. satellites: 6

Maximum amplitude: 131072 / 131072

$-555-742-808$

$-593-900-616$

$-764-951-705$

$-781-349-953$

(...)

Figure 8 

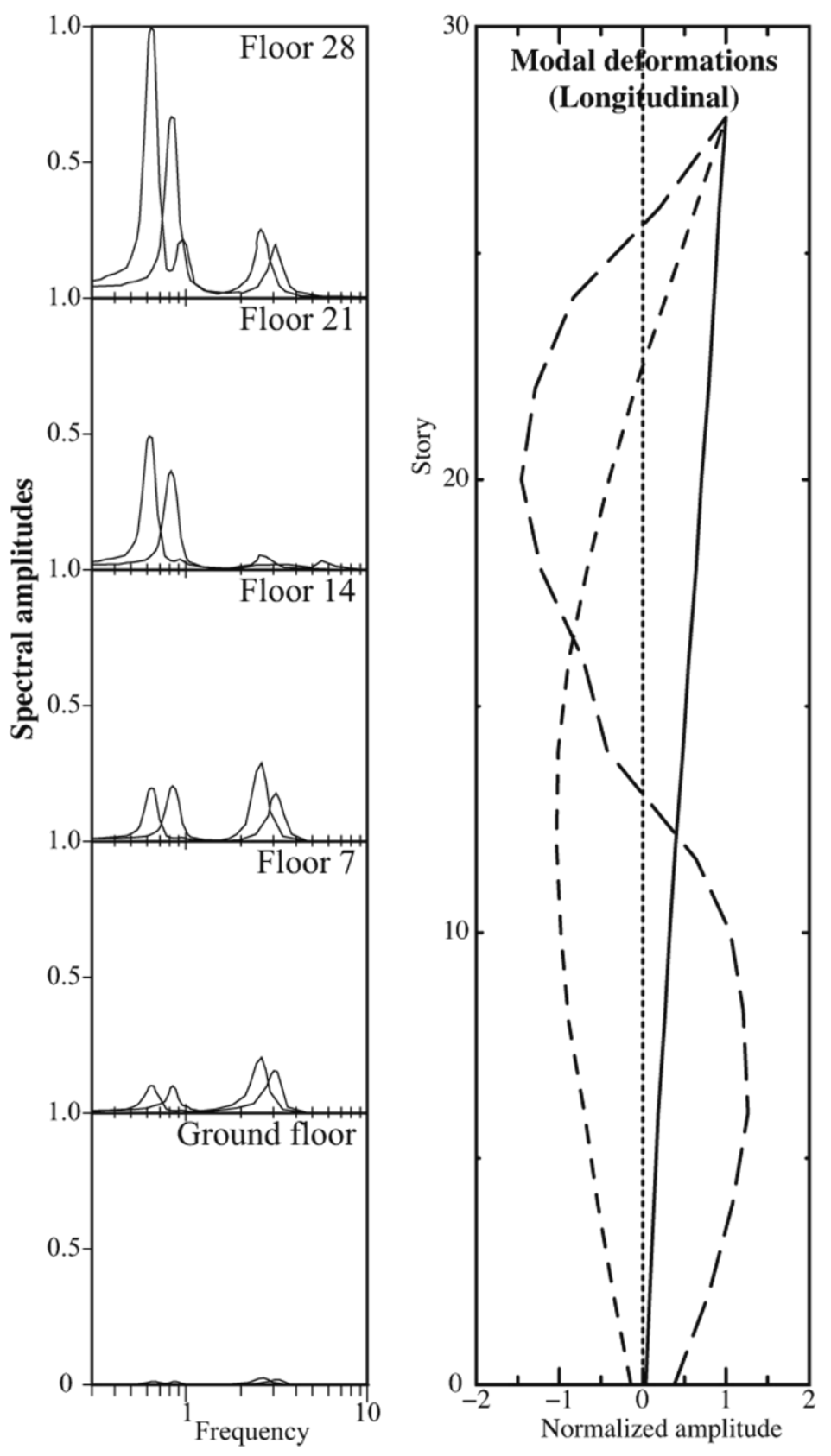

Figure 9 

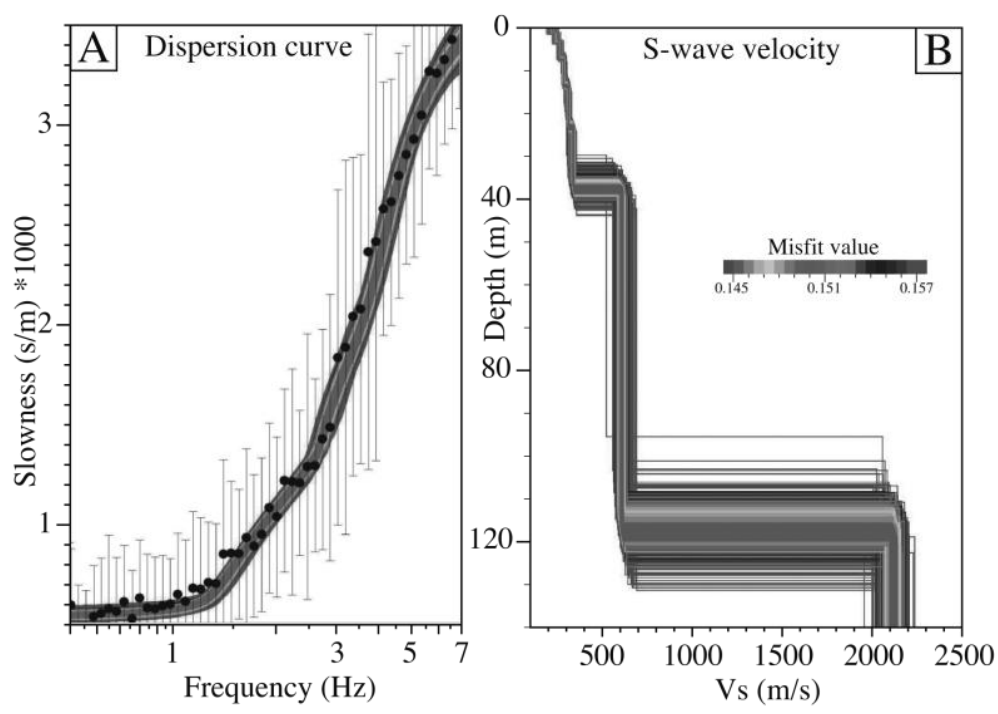

Figure 10 